\author{
Т.Н. Березина
}

\title{
ПСИХОГЕНЕТИЧЕСКИЙ АНАЛИЗ ИНДИВИДУАЛЬНОЙ ПРОДОЛЖИТЕЛЬНОСТИ ЖИЗНИ
}

\begin{abstract}
Аннотация. Индивидуальная продолжительность жизни рассматривается как психогенетический признак, анализируется влияние факторов наследственности и среды на его выраженность. Отмечается, что на индивидуальную продолжительность жизни влияют оба эти фактора, приводятся данные анализа литературы $c$ доказательством влияния фактора наследственности и фактора среды. В качестве доказательств роли наследственности приводятся: запрограммированное количество клеточных делений, наличие "генов смерти», существование "биологических часов" и т.п. К доказательствам роли среды отнесены: изменение продолжительности жизни лабораторных животных под влиянием фракторов среды, наличие негенетических причин старения, существование феномена "обратимости старения" у некоторых живых существ и т.п. Описывается собственное эмпирическое исследование, выполненное классическим близнецовым методом. на 100 парах монозиготных близнецов и 70 парах дизиготных близнечов, проживавших в РФ в XX-XXI в8., приводятся его результаты. Отмечается, что средние различия в продолжительности жизни монозиготных близнецов в парах достигают 9,4 года, а дизиготных - 12,3 лет. Приводятся данные корреляционного анализа, согласно которому показатель взаимосвязи по признаку индивидуальной продолжительности жизни в парах Мз-близнецов равен 0,91, а Д3-0,73. На основании полученных данных делается вывод о преимущественном влиянии общей и близкой среды на индивидуальную продолжительность в нашей стране в изучаемый период времени.

Ключевые слова: психология, психогенетика, индивидуальная продолжительность жизни, близнецовый метод, монозиготные близнецы, дизиготные близнецы, наследственность, среда, теории старения, личностная организация времени.

Abstract. Individual life expectancy is viewed by the author as a psychogenetic attribute. In her research Berezina analyzes the influence of heredity and environment on life expetency. Berezina emphasizes that both factors have the influence on life expectancy and provides the results of the analysis of academic literature proving the influence of heredity and environment. The main proof of the great role of heredity on life expetancy involves: pre-programmed amount of cell divisions, so called 'death genes', 'biological clock' and etc. The main proof of the great role of the environment on life expectancy includes: life expectancy of laboratory animals influenced by the environmental factors, non-genetic aging causes, phenomenon of 'reverse aging' demonstrated by some living creatures, etc. The author also provides the results of her own empirical research using the classical twin method. 100 monozygotic twins and 70 dizygotic twins living in the Russian Federation in the XXth-XXIst centuries were studied. Based on the results of the research, the mean difference in life expectancy was 9, 4 years for monozygotic twins and 12,3 for dizygotic twins. The results of the correlation analysis provide the correlation of individual life expectancy being 0,91 for monozygotic twins and 0,73 for dizygotic twins. Based on the results of the research, the author concludes that the overall and proximate environment has had the dominating effect on individual life expectancy in our country during the period of time under review.
\end{abstract}

Key words: theories of aging, environment, heredity, monozygotic twins, dizygotic twins, twin method, individual life expectancy, psychogenetics, psychology, personal organization of time.

И

ндивидуальную продолжительность жизни можно рассматривать как сложный психогенетический признак. Под признаком в психогенетике понимают условное

обозначение единицы поведенческой, физиологической, морфологической, биохимической и др. дискретности индивидов, позволяющей отличить одного индивида от другого. На степень выражен-

Исследование выполнено при финансовой поддержке РГНФ, проект № 16-06-50020 «Влияние факторов личностной организации жизненного пути на индивидуальную продолжительность жизни в РФ в ХХ-ХХІ вв.». 


\section{Психология и психотехника 3(90) • 2016}

ности у индивида любого признака, в том числе и продолжительности жизни, влияют факторы среды и наследственности, а также их взаимодействие. Одна из задач психогенетики - установить соотносительную роль этих факторов. Традиционно индивидуальная продолжительность жизни рассматривалась в аспекте медицины [1], биологии [2], физиологии [3], геронтологии [4], утверждавших те или иные причины её выраженности. Однако интересным будет рассмотреть индивидуальную продолжительность жизни как психогенетический признак, используя наработанную методологию психогенетики [5]. Существующие доказательства роли наследственности включают в себя: запрограммированную продолжительность жизни отдельных клеток организма, существование «генов смерти», генетическую детерминацию синдрома ускоренной смерти, наличие «молекулярно-биологических часов» в хромосомах, связанных с явлением старения.

Продолжительность жизни организма может быть закодирована на клеточном уровне через ограничение количества делений соматических клеток. В 1961 г. Л. Хейлик доказал, что клетки человека, живущие в клеточной культуре, умирают приблизительно после 50 делений и проявляют признаки старения при приближении к этой границе - в настоявшее время это называется «предел Хейфлика» [6].

Существование «генов смерти» убедительно доказано молекулярными генетиками Р. Горвицем, С. Бреннером и Дж. Салстоном, в 2002 г. получившими Нобелевскую премию в области медицины и физиологии за открытие ключевых генов, регулирующих развитие органов и апоптоз - запрограммированную смерть клеток. Работа велась на протяжении нескольких десятилетий, авторы выделили гены, которые управляли развитием организма нематод, и проследили их действие от момента возникновения организма из оплодотворенной клетки до его гибели. На основании этой работы было открыто явление апоптоза - запрограммированной клеточной смерти. Исследование является очень важным и для психогенетики, потому что авторами было показано, что, по крайней мере, два гена «смерти», выделенных у нематод, имеют свои аналоги в геноме человека [7].

Многие исследователи, подчёркивая роль генов в регуляции продолжительности жизни, в качестве доказательства приводят явление прогерии синдрома ускоренного старения - заболевания, при котором организм человека развивается ускоренно и быстро стареет (средняя продолжительность жизни при детской прогерии - 13 лет, у взрослой - зависит от момент начала заболевания). Этот синдром имеет чёткую генетическую обусловленность, аутосомно-рецессивный тип наследования, выделен ген, отвечающий за его проявление (для взрослой прогерии ген - WRN). Исследователи установили, что одна из самых тяжёлых форм взрослой прогерии - синдром Хатчинсона-Гилфорда, ведёт к тем же изменениям в организме, что и нормальное старение: с геномной нестабильностью, нарушением гомеостаза стволовых клеток, уменьшение длины тепломер и др. Эти данные привели авторов к гипотезе, предполагающей, что при прогерии патологически ускоряется ряд процессов, которые обычно управляют естественным старением [8].

Под понятием «молекулярно-генетические биологические часы» понимают внутриклеточные механизмы, связанные с укорачиванием теломер при каждом последующем удвоении хромосом. В настоящее время считается, что практически весь генетический материал у человека находится в хромосомах, с обоих концов каждая хромосома закрыта концевыми участками - теломерами. При делении клетки происходит удвоение хромосом на всём их протяжении за исключением участка теломер. Поэтому хромосомы становятся чуть короче при каждом последующем делении клетки. Таким образом, по длине хромосом можно установить возраст (количество происшедших делений клетки) [9].

Однако большинство авторов всё-таки останавливаются на преимущественной роли среды в определении длительности индивидуальной жизни. «Вопреки широко распространённому мнению, никаких убедительных доказательств преимущества генетической природы наблюдаемых индивидуальных различий по срокам жизни не имеется. Более того, многочисленные данные свидетельствуют скорее о том, что вклад генетической гетерогенности в наблюдаемые различия, по-видимому, невелик» [10, с. 40-41].

К доказательствам роли фактора среды относят: наличие внешних биологических (негенетических) причин старения, существование феномена обратимости старения у некоторых видов живых существ под влиянием характеристик среды, увеличение продолжительности жизни у лабораторных животных путём манипулирования факторами среды, незначительные корреляции (или их полное отсутствие) между продолжительностью жизни поколений детей и отцов, влияние внешних (социальных, экономических, политических и т.п.) причин сокращения продолжительности жизни в некоторых странах.

В.И. Донцов, проанализировав существующие причины старения организмов, выделяет четыре механизма, которые предполагают внешнюю детерминацию негенетического характера: потеря 
элементов организма, которые не способны к обновлению; накопление деформаций и повреждений клеточного и внутриклеточного характера, системное «загрязнение» организма в течении времени как следствие его недостаточной открытости как системы, а также неблагоприятные изменения процессов регуляции и системные изменения самой регуляции различного характера [11].

Другим доказательством средовой модели является факт обратимости старения - феномен негативного старения (или антистарения). В онтогенезе некоторых живых существ встречаются периоды, когда с возрастом происходит увеличение надёжности всех систем организма, вероятность смерти уменьшается, и, как правило, вырастает плодовитость; среди видов, имеющих в своём онтогенезе такой период, называют: кораллы, черемшу, бурые водоросли, некоторые деревья, брюхоногих моллюсков, червей, морских окуней и даже человека [12]. Наличие в онтогенезе такого периода, позволяет исследователям сделать вывод, что индивидуальная продолжительность жизни зависит не от генетической детерминации, а от «системного расхождения и дисрегуляторной патологии» [13, с. 8].

Известно большое количество экспериментальных исследований увеличения продолжительности жизни лабораторных животных путём специального варьирования факторами среды. Существуют данные, показывающие, что путём специального модулирования внешних сигнальных стимулов удалось увеличить срок жизни нематод в 10 раз [14]. Есть аналогичные исследования, выполненные на млекопитающих. При создании идеальных условий у мышей - срок жизни может увеличиться в 3 раза, а понижении температуры тела хомяков приводит к двукратному увеличению продолжительности жизни [15]. У мышей и крыс разных линий максимальная продолжительность жизни достоверно увеличивалась в среднем на 16\% при ограничении питания [9].

Данные психогенетических исследований, выполненных генеалогическим методом, по мнению Э. Мэрфи, также подтверждают влияние фактора среды, а имеющиеся место коэффициенты корреляции (очень незначительные) между продолжительностью жизни родителей и их потомков, по его мнению, обусловлены не наследственностью, а культурными и средовыми особенностям, и связаны скорее с семейными традициями [16].

На продолжительность жизни также влияют экономические, политические и социальные условия в данном социуме. Свидетельством этому является факт зависимости средней продолжительности жизни от страны проживания и от исторического периода. По данным антропологов, среднестатистическая продолжительность жизни человека возрастала от эпохи палеолита (20-22 года) до наших дней, при этом наибольший прирост её наблюдается в последние два века [17]. В настоящее время средняя продолжительность жизни человека колеблется от 32,2 в Свазиленде (южная часть Африки) до 82,75 в Андорре (юго-западная часть Европы) [18]. Существуют также данные о влиянии на индивидуальную продолжительность жизни факторов организации личностью её жизненного пути [19], например, стрессогенных факторов, которые могут способствовать как увеличению, как и уменьшению её длительности [20].

Ранее мы предположили, что норма реакции признака индивидуальной продолжительности жизни очень велика, и если верхняя её граница будет определяться наследственностью, то нижняя средой [21]. Многие авторы отмечали, что верхняя граница продолжительности жизни находится под контролем генов, об этом свидетельствует тот факт, что долгожительство во многих популяциях оказывается наследственным [22]. Этот факт известен для долгожителей Японии [23], Китая [24]. По мнению У. Броунера и коллег: «Очень длинная жизнь, за возраст 90 или 100 лет, судя по всему, в сильной степени зависит от генетики» [25, с. 851].

Доказательством того, что нижняя граница нормы реакции признака «индивидуальная продолжительность жизни» зависит от средовых факторов, является факт ранней детской смертности, поскольку смерть детей в этом возрасте, чаще всего, определяется именно средой: или враждебной или недостаточно заботливой по отношению к незрелорождённым детёнышам.

Таким образом, и гены, и среда вносят свой вклад, а вот в качестве соотношения между ними, мы бы привели точку зрения исследователей из Калифорнийского тихоокеанского медицинского центра. Сравнивая продолжительность жизни у близнецов и других членов семьи, они обнаружили, что до 25\% вариации в продолжительности жизни человека является наследственным, а остальные 75\% связано с воздействия окружающей среды, несчастными случаями и травмами, и действием случайности [25]. Близкие цифры называют и другие исследователи [26; 27].

Однако, несмотря на большое количество исследований в этой области, в психогенетическом аспекте проблема далека от окончательного решения.

Причин этого, на наш взгляд две. Во-первых, большинство исследований индивидуальной продолжительности жизни выполнено биографическим, генеалогическим или корреляционным методом, в то время как для оценки соотносительной 


\section{Психология и психотехника 3(90) • 2016}

роли наследственности и среды наиболее информативным является близнецовый. Во-вторых, имеющиеся близнецовые исследования проводились на людях, живших в XIX-м и первой половине XXго века [28], или выполнены на материале других стран, как приводимые У. Броунером [25]. С учётом того, что средняя продолжительность жизни в значительной степени зависит от места обитания и от исторического периода, мы полагаем, что вклад факторов среды и наследственности будет разным для разных стран и эпох. Всё это делает актуальным проведение исследования соотносительной роли среды и наследственности в проявлении психогенетического признака «индивидуальная продолжительность жизни» в нашей стране в XXXXI вв. Именно этой проблеме и посвящено наше исследование.

\section{Организация исследования}

Цель исследования - выделение вклада двух факторов (наследственности и среды), влияющих на индивидуальную продолжительность жизни в нашей стране классическим близнецовым методом.

Гипотеза. Мы предполагаем, что в настоящее время в нашей стране индивидуальная продолжительность жизни преимущественно будет зависеть от факторов среды, а не наследственности.

При этом наличие значительных различий в степени корреляционной связанности признака у исследуемых групп близнецов будет говорить о преобладании фактора наследственности, незначительные различия в степени связанности признака у исследуемых групп близнецов будет говорить о преимущественной роли среды, определяющей длительность индивидуальной жизни в нашей стране в XX-XXI вв.

\section{Методы исследования}

1. Классический близнецовый метод, предполагающей сравнение степени выраженности признака у монозиготных и дизиготных близнецов.

2. Методы математической статистки. Вычисление показателей описательной статистики и коэффициента коррекции Пирсона.

Испытуемые. В соответствии с методологией классического близнецового метода были взяты две группы близнецов, годы жизни которых приходились на XX-XXI вв. Для исследования брались пары, в которых оба близнеца миновали детский возраст (пары, в которых один из близнецов погибал при родах или в детстве в выборку не включались). 1 груп- па - монозиготные близнецы - 100 пар. В рамках этой группы выделялась подгруппа МЗ-близнецы, пары, в которых оба близнеца умерли естественной смертью (таковых у нас было - 40\%), сюда не включались пары, в которых один или оба близнеца умирали насильственной смертью, от несчастных случаев, а также случаи, в которых причины смерти установить точно не удалось. 2 группа - дизиготные близнецы - 70 пар - все пары однополые. В рамках этой группы также выделялась подгруппа ДЗ-близнецы, пары, в которых оба близнеца умерли естественной смертью (таковых у нас было - 36\%), сюда не включались пары, в которых один или оба близнеца умирали насильственной смертью, от несчастных случаев, а также случаи, в которых причины смерти установить точно не удалось.

В обеих группах близнец, имеющий большую продолжительность жизни, назывался «близнец - долгожитель», а индивид с меньшей продолжительностью жизни - «второй близнец».

Метод подбора испытуемых - произвольная выборка. Поиск близнецов осуществлялся среди родственников студентов, в настоящее время обучающихся в Московских вузах. Студенты проводили опрос старших членов своей семьи на предмет наличия среди родственников - близнецов, завершивших свой жизненный путь. При наличии таких близнецов, их родственники заполняли специальную анкету, в которой нужно было указать пол, зиготность, годы жизни близнецов и причины смерти. Было опрошено несколько тысяч студентов, и, соответственно, подобрано 170 пар близнецов. Зиготность определялась на основании опроса, т.е. принималась таковой, какой она считалась при жизни.

\section{Результаты исследования и их анализ}

Мы изучили среднюю продолжительность жизни близнецов в паре. Как показало наше исследование, средняя разница продолжительности жизни в парах М3-близнецов равна 9,4 годам, а для близнецов, умерших естественной смертью, она оказывается равной 7,1 лет. Для дизиготных близнецов разница между средней продолжительностью жизни оказывается ещё больше, чем у монозиготных, и достигает 12,3 лет, а для умерших естественной смертью 11,7 лет.

Монозиготные близнецы имеют $100 \%$ общих генов, в то время как дизиготные - в среднем 50\%, при этом те и другие пары имели практически одинаковую среду на протяжении полутора-двух первых десятилетий онтогенеза, далее среда постепенно стала различаться. Такая динамика соответствует обычному развитию близнецов и явля- 


\section{Индивид и личность}

ется стандартной для классического близнецового метода. Следует отметить, что таковой динамика является и для пар моно- и дизиготных близнецов.

Рассмотрим среднюю продолжительность жизни по нашей выборке и сравним её со средней продолжительностью жизни в нашей стране. Следует отметить, что средняя продолжительность жизни всех МЗ-близнецов (и долгожителей и вторых) равна 53,5 лет, а Д3-близнецов - 54,3 года. Наша выборка была составлена из людей, родившихся в XX в. и умерших как в первой (несколько пар погибли на Великой Отечественной войне), так и во второй половине XX в., а также в XXI в. Следует учесть, что средняя продолжительность жизни на протяжении этого времени менялась: если с 1960 до 2000 она колебалась в районе 64-70 лет, то демографические данные по первой половине и середине XX в. отсутствуют, известно лишь следующее, что она увеличивалась от 32 лет до 64-70 к 60-м гг. $\mathrm{XX}$ в. [17]. Так что полученные нами цифры вполне соответствуют средней продолжительности жизни в нашей стране в изучаемый период времени.

Важнейшим результатом наших исследований, мы считаем, является установление средней разницы продолжительности жизни МЗ-близнецов в паре. Для общей выборки - это 9,4 года, а для подвыборки МЗ-близнецов, умерших своей смертью, это 7,1 год. Разница в продолжительности жизни, полученная в нашем исследовании, отличается от аналогичных данных А. Джакварда, полученных в 1982 г. на англо-американской выборке. Он получил следующие данные: у монозиготных близнецов различия в продолжительности жизни составляют 3,0 года, а у дизиготных - 6,2 года [28].

Это достаточно большой промежуток времени, в течение которого один человек продолжал жить, а другой - погибал. Причём погибал человек с таким же набором генов, с общей семейной средой, начинающий свой взрослый путь от такого же материального положения и социального статуса, имеющие те же самые интеллектуальные и творческие задатки, которые могут влиять на индивидуальную продолжительность жизни [29]. Это промежуток времени, на который можно увеличить или уменьшить индивидуальную продолжительность в зависимости от самой личности, её способностей [30] и её взрослого жизненного пути, иначе говоря, от личностной организации времени своей жизни [31]. Многие авторы отмечали, что активность личности может повлиять, в том числе и на её продолжительность жизни (подробнее [32]), но выявление конкретных факторов, влияющих на величину этого промежутка, также является делом будущих исследований.
Как мы отмечали выше, в настоящее время наибольшей популярностью пользуется точка зрения, что индивидуальная продолжительность жизни на $25 \%$ определяется наследственностью, а на 75\% средой [25], и данные нашего предыдущего близнецового исследования подтверждали это [33].

В настоящей работе мы также попытались установить соотношение между факторами среды и наследственности в соответствии с коэффициентами внутрипарной корреляции и формулой Игнатьева. Как показал корреляционный анализ, наблюдается достоверная взаимосвязь индивидуальной продолжительности жизни как в парах МЗблизнецов $(\mathrm{r}=0,91)$ и Д3-близнецов $(\mathrm{r}=0,73)$, при этом взаимосвязь сильнее выражена в монозиготных парах. В соответствии с формулой Игнатьева, это означает, что 64\% дисперсии определяется средой, и лишь 36\% - наследственностью.

Таким образом, наше исследование подтверждает выдвинутую нами гипотезу о преимущественной роли факторов среды в формировании индивидуальной продолжительности жизни.

\section{Заключение}

Проблема индивидуальной продолжительности жизни и факторов, влияющих на неё, является актуальной, особенно в свете грядущей пенсионной реформы. Как пишут В.Н. Крутько, В.И. Донцов: «Резкое постарение населения и развитие хронических заболеваний с возрастом приводит ко всё большему вложению средств в программы лечения старых лиц и увеличению объёма выплат пенсионного и социального обеспечения без ощутимой отдачи обществу результатов такого использования материальных ресурсов. Изменения структуры занятости требуют заблаговременной адаптации и серьёзной перестройки социальных служб и бюджетных ресурсов. Несомненно, сходные траты вынуждена будет осуществлять и Россия, в которой, в связи с резким падением рождаемости и экономическим спадом, последствия постарения населения представляются вдвойне катастрофичными и являются “проблемой популяционной безопасности", напрямую связанной с возможностями сохранения трудового и оборонного потенциала страны» [34, с. 147].

Именно для того, чтобы найти решение этой метазадачи «сохранения трудового и оборонного», тем более в свете ожидаемой пенсионной реформы необходимо как установить соотношение между факторами среды и наследственности, влияющими на индивидуальную продолжительность жизни, так и определить, какие именно факторы среды и таким образом влияют на неё. 


\section{Психология и психотехника 3(90) • 2016}

Как показало наше исследование, в настоящее время в нашей стране, индивидуальная продолжительность жизни зависит преимущественно от среды (64\%) и в меньшей степени от наследственности (36\%). Мы можем отметить значительные различия в индивидуальной продолжительности монозиготных близнецов в паре. Средняя разница прожитых лет у МЗ-близнецов 9,4 года (а у Д3близнецов - на 12,3 года). Это достаточно большой срок, на который один человек, пережил другого, имеющего точно такой же набор генов, общих родителей, общую детскую среду и воспитание. Это установленный нами факт. И он требует продолжения исследований, чтобы установить, какие именно факторы повлияли в данном случае, чтобы увеличить продолжительность жизни одного близнеца и уменьшить другого. Выявление этих факторов откроет дорогу сознательному управлению человеком временем своей жизни и своим жизненным путём так, чтобы увеличить длительность здорового и продуктивного периода существования.

\section{Список литературы:}

1. Тодоров И.Н., Тодоров Г.И. Стресс, старение и их биохимическая коррекция. М.: Наука, 2003. 479 с.

2. Terman A., Kurz T., Gustaffson B., Brunk U. The involment of lysosomes in myocardial aging and disease // Curr Cardiol Rev. 2008 May. № 4(2). P. 107-115.

3. Анисимов В.Н. Молекулярные и физиологические механизмы старения. М.: Наука, 2003. 468 с.

4. Чернилевский В.Е. Участие биоритмов организма в процессах развития и старения. Гипотеза резонанса // Доклады МОИП. Т. 41. Секция Геронтологии. Сборник статей. М.: МОИП: Мультипринт, 2008. С. 123-138.

5. Березина Т.Н. Вероятностная модель продолжительности жизни // Психология и психотехника. 2013. № 4. С. 390-400.

6. Hayflick L., Moorhead P.S. The serial cultivation of human diploid cell strains // Exp. Cell Res. 1961. V. 253. P. 585-621.

7. Скулачев В.П. По физиологии и медицине С. Бреннер, Х.Р. Хорвиц, Дж. Салстон // Природа. 2003. № 1. С. 76-77.

8. Burtner C.R., Kennedy B.K. Progeria syndromes and ageing: what is the connection? // Nature Reviews Molecular cell Biology. 2010. V. 11. P. 567-578. DOI:10.1038/nrm2944.

9. Фролькис В.В., Мурадян Х.К. Экспериментальные пути продления жизни. Л.: Наука, 1988. 248 с.

10. Гаврилов Н.А., Гаврилова Н.С. Биология продолжительности жизни. М.: Наука, 1991. 280 с.

11. Донцов В.И. Перспективные направления и методы. Обзор мировых тенденций // Доклады МоИП. Т. 41. Секция Геронтологии. Сборник статей. М.: МОИП Мультипринт, 2008. С. 165-167.

12. Vaupel J.W., Baudisch A., Dolling M., et al. The case for negative senescence // Theor. Popul. Biol. 2004. Vol. 65. P. 339-351.

13. Халявин А.В., Крутько В.Н. Первопричины старения и обратимость этого процесса // Доклады МОИП. Т. 48. Секция Геронтологии. Сборник статей. М.: МОИП, Цифровичок. 2011. C. 7-11.

14. Ayyadevara S., Alla R., Thaden J.J., Shmookler Reis R.J. Remarkable longevity and stress resistance of nematode PI3K-null mutants // Aging Cell. 2008. Vol. 7. P. 13-22. Hayflick L., Moorhead P.S. The serial cultivation of human diploid cell strains // Exp. Cell Res. 1961. V. 253. P. 585-621.

15. Lyman C.P. Hibernation and longevity in the turkish hamster // Science. 1981. Vol. 212. P. 668-670.

16. Murphy E.A. Genetics of longevity in man // The Genetics of Aging. N.Y.: Plenum Press, 1978. P. 261-301.

17. Волгин Н.А. Демография. М.: Изд-во РАГС, 2003. 384 с.

18. О странах. Географический справочник. URL: http://ostranah.ru/_lists/life_expectancy.php.

19. Березина Т.Н.Психологические особенности и механизмы стрессогенных факторов в профессии лётчик-космонавт // Человеческий капитал. 2015. № 5(77). С. 134-137.

20. Березина Т.Н., Мансуров Э.И. Влияние стрессогенных факторов на продолжительность жизни летчиков-космонавтов // Вопросы психологии. 2015. № 3. С. 73-83.

21. Березина Т.Н. Факторы среды и их влияние на индивидуальную продолжительность жизни. // Мир психологии. 2013. № 4. C. 165-178.

22. Perls T.T., Wilmoth J., Levenson R., et al. Life-long sustained mortality advantage of siblings of centenarians. Proc Natl Acad Sci USA, 2002. 99:8442-7.

23. Willcox D.C., Willcox B.J., Hsueh W.C., Suzuki M. Genetic determinants of exceptional human longevity: insights from the Okinawa Centenarian Study // Age (Dordr). 2006 Dec. № 28(4). P. 313-332.

24. Danzhen Y., Danan G., Zeng Y. Familial Transmission of Human Longevity Among the Oldest-Old in China // Journal of Applied Gerontology. June 2010. Vol. 29. № 3. P. 308-332.

25. Browner W.S., Kahn A.J., Ziv E., Reiner A.P., Oshima J., Cawthon R.M., Hsueh W.C., Cummings S.R. The genetics of human longevity // Am J Med. 2004. №117(11). P. 851-860.

26. Korpelainen H. Variation in the heritability and evolvability of human life span // Naturwissenschaften. 2000. № 87. P. $566-568$.

27. Herskind A.M., McGue M., Holm N.V., Sørensen T.I., Harvald B., Vaupel J.W. The heritability of human longevity: a populationbased study of 2872 Danish twin pairs born 1870-1900 // Human Genetics. 1996. № 97. P. 319-323.

28. Jacquard A. Heritability of human longevity // Biological and Social Aspects of Mortality and the Length of life / Ed. H.S. Preston. Liege, 1982.

29. Дружинин В.Н. Психология общих способностей. СПб.: Питер, 2007. 368 с.

30. Березина Т.Н. Социальная креативность и социальный интеллект в структуре общих способностей // Психология обучения. 2016. № 2. С. 68-81.

31. Абульханова К.А. Личностная организация времени жизни // Мир психологии. 2011. № 3. С. 93-104.

32. Березина Т.Н. Творческая активность в структуре самоотношения и утверждении самости как фактор антистарения // Мир психологии. 2010. № 4. С. 130-141. 


\section{Индивид и личность}

33. Березина Т.Н. Анализ продолжительности жизни известных монозиготных близнецов с позиций субъектного подхода // NB: Психология и психотехника. 2013. № 5. С. 1-10.

34. Березина Т.Н. Вероятностный подход к продолжительности жизни в современных теориях старения // Психолог. 2016. № 1. C. 93-106. DOI: 10.7256/2409-8701.2016.1.18716. URL: http://www.e-notabene.ru/psp/article_18716.html.

35. Гуревич П.С. Современный век и его святыни (окончание) // Педагогика и просвещение. 2012. № 4. С. 3-5.

\section{References (transliterated):}

1. Todorov I.N., Todorov G.I. Stress, starenie i ikh biokhimicheskaya korrektsiya. M.: Nauka, 2003. 479 s.

2. Terman A., Kurz T., Gustaffson B., Brunk U. The involment of lysosomes in myocardial aging and disease // Curr Cardiol Rev. 2008 May. № 4(2). P. 107-115.

3. Anisimov V.N. Molekulyarnye i fiziologicheskie mekhanizmy stareniya. M.: Nauka, 2003. $468 \mathrm{~s}$.

4. Chernilevskii V.E. Uchastie bioritmov organizma v protsessakh razvitiya i stareniya. Gipoteza rezonansa // Doklady MOIP. T. 41. Sektsiya Gerontologii. Sbornik statei. M.: MOIP: Mul'tiprint, 2008. S. 123-138.

5. Berezina T.N. Veroyatnostnaya model' prodolzhitel'nosti zhizni // Psikhologiya i psikhotekhnika. 2013. № 4. S. 390-400.

6. Hayflick L., Moorhead P.S. The serial cultivation of human diploid cell strains // Exp. Cell Res. 1961. V. 253. P. 585-621.

7. Skulachev V.P. Po fiziologii i meditsine S. Brenner, Kh.R. Khorvits, Dzh. Salston // Priroda. 2003. № 1. S. 76-77.

8. Burtner C.R., Kennedy B.K. Progeria syndromes and ageing: what is the connection? // Nature Reviews Molecular cell Biology. 2010. V. 11. P. 567-578. DOI:10.1038/nrm2944.

9. Frol'kis V.V., Muradyan Kh.K. Eksperimental'nye puti prodleniya zhizni. L.: Nauka, 1988. 248 s.

10. Gavrilov N.A., Gavrilova N.S. Biologiya prodolzhitel'nosti zhizni. M.: Nauka, 1991. 280 s.

11. Dontsov V.I. Perspektivnye napravleniya i metody. Obzor mirovykh tendentsii // Doklady MOIP. T. 41. Sektsiya Gerontologii. Sbornik statei. M.: MOIP Mul'tiprint, 2008. S. 165-167.

12. Vaupel J.W., Baudisch A., Dolling M., et al. The case for negative senescence // Theor. Popul. Biol. 2004. Vol. 65. P. $339-351$.

13. Khalyavin A.V., Krut'ko V.N. Pervoprichiny stareniya i obratimost' etogo protsessa // Doklady MOIP. T. 48. Sektsiya Gerontologii. Sbornik statei. M.: MOIP, Tsifrovichok. 2011. S. 7-11.

14. Ayyadevara S., Alla R., Thaden J.J., Shmookler Reis R.J. Remarkable longevity and stress resistance of nematode PI3K-null mutants // Aging Cell. 2008. Vol. 7. P. 13-22. Hayflick L., Moorhead P.S. The serial cultivation of human diploid cell strains // Exp. Cell Res. 1961. V. 253. P. 585-621.

15. Lyman C.P. Hibernation and longevity in the turkish hamster // Science. 1981. Vol. 212. P. 668-670.

16. Murphy E.A. Genetics of longevity in man // The Genetics of Aging. N.Y.: Plenum Press, 1978. P. 261-301.

17. Volgin N.A. Demografiya. M.: Izd-vo RAGS, 2003. 384 s.

18. O stranakh. Geograficheskii spravochnik. URL: http://ostranah.ru/_lists/life_expectancy.php.

19. Berezina T.N. Psikhologicheskie osobennosti i mekhanizmy stressogennykh faktorov v professii letchik-kosmonavt // Chelovecheskii capital. 2015. № 5(77). S. 134-137.

20. Berezina T.N., Mansurov E.I. Vliyanie stressogennykh faktorov na prodolzhitel'nost' zhizni letchikov-kosmonavtov // Voprosy psikhologii. 2015. № 3. S. 73-83.

21. Berezina T.N. Faktory sredy i ikh vliyanie na individual'nuyu prodolzhitel'nost' zhizni. // Mir psikhologii. 2013. № 4. S. $165-178$.

22. Perls T.T., Wilmoth J., Levenson R., et al. Life-long sustained mortality advantage of siblings of centenarians. Proc Natl Acad Sci USA, 2002. 99:8442-7.

23. Willcox D.C., Willcox B.J., Hsueh W.C., Suzuki M. Genetic determinants of exceptional human longevity: insights from the Okinawa Centenarian Study // Age (Dordr). 2006 Dec. № 28(4). P. 313-332.

24. Danzhen Y., Danan G., Zeng Y. Familial Transmission of Human Longevity Among the Oldest-Old in China // Journal of Applied Gerontology. June 2010. Vol. 29. № 3. P. 308-332.

25. Browner W.S., Kahn A.J., Ziv E., Reiner A.P., Oshima J., Cawthon R.M., Hsueh W.C., Cummings S.R. The genetics of human longevity // Am J Med. 2004. №117(11). P. 851-860.

26. Korpelainen H. Variation in the heritability and evolvability of human life span // Naturwissenschaften. 2000. № 87. P. $566-568$.

27. Herskind A.M., McGue M., Holm N.V., Sørensen T.I., Harvald B., Vaupel J.W. The heritability of human longevity: a populationbased study of 2872 Danish twin pairs born 1870-1900 // Human Genetics. 1996. № 97. P. 319-323.

28. Jacquard A. Heritability of human longevity // Biological and Social Aspects of Mortality and the Length of life / Ed. H.S. Preston. Liege, 1982.

29. Druzhinin V.N. Psikhologiya obshchikh sposobnostei. SPb.: Piter, 2007. 368 s.

30. Berezina T.N. Sotsial'naya kreativnost' i sotsial'nyi intellekt v strukture obshchikh sposobnostei // Psikhologiya obucheniya. 2016. № 2. S. 68-81.

31. Abul'khanova K.A. Lichnostnaya organizatsiya vremeni zhizni // Mir psikhologii. 2011. № 3. S. 93-104.

32. Berezina T.N. Tvorcheskaya aktivnost' v strukture samootnosheniya i utverzhdenii samosti kak faktor antistareniya // Mir psikhologii. 2010. № 4. S. 130-141.

33. Berezina T.N. Analiz prodolzhitel'nosti zhizni izvestnykh monozigotnykh bliznetsov s pozitsii sub"ektnogo podkhoda // NB: Psikhologiya i psikhotekhnika. 2013. № 5. S. 1-10.

34. Berezina T.N. Veroyatnostnyi podkhod k prodolzhitel'nosti zhizni v sovremennykh teoriyakh stareniya // Psikholog. 2016. № 1. S. 93-106. DOI: 10.7256/2409-8701.2016.1.18716. URL: http://www.e-notabene.ru/psp/article_18716.html.

35. Gurevich P.S. Covremennyi vek i ego svyatyni (Okonchanie) // Pedagogika i prosveshchenie. 2012. № 4. S. 3-5. 